\title{
ERRATUM
}

\section{Nonlinear aspects of energy dissipation in wood-panel joints}

\author{
by Sara Casciati \\ ASTRA Dept., School of Architecture, University of Catania at Siracusa, 96100 Siracusa, Italy
}

Erratum to: Earthq Engrg \& Engrg Vib (Vol.6 No.3, pp.259-268, September 2007)

DOI: $10.1007 / \mathrm{s} 11803-007-0764-9$

We have found some mistakes in the article by Sara Casciati (2007). The revisions are given below:

1. The last sentence of the first paragraph in p.262 "(Casciati and Faravelli, 2007)" should be changed to "(Casciati and Faravelli, 1991)".

2. The reference No.7 "Casciati F and Castera P (2007), Structural Safety, 29(4): 253-348” should be changed to "Casciati F and Castera P (2007), "Guest Editors' Preface," Structural Safety, 29(4): 253-348”.

\section{References}

Sara Casciati (2007), "Nonlinear Aspects of Energy Dissipation in Wood-panel Joints," Earthquake Engineering and Engineering Vibration, 6(3): 259-268. 